\title{
Functional Glycomics
}

\section{(Li Jianjun (ed.), in Methods in Molecular Biology, Vol. 600, J. Walker (ser. ed.), Humana Press, 2010, 284 p., \$99)}

DOI: $10.1134 / \mathrm{S} 0006297910110155$

The book consists of 19 chapters prepared by an international team of authors.

Chapter 1 and 2 give a historical overview in functional glycomics and glycobiology and glycoanalysis, respectively. Chapter 3 highlights quantitative glycomics and includes a range of modern procedures for quantitation of various types of carbohydrates.

Chapter 4 is devoted to characterization and role of gangliosides and bacterial lipooligosaccharides in the development of autoimmune neuropathies.

Chapter 5 includes data about biotinylated multivalent glycoconjugates for surface coating.

Chapter 6 characterizes profiling lipopolysaccharide glycoforms of non-typeable Haemophilus influenzae by multiple-stage tandem mass spectrometry.

Chapter 7 includes data about reconstitution in vitro of the O-antigen repeating unit of Escherichia coli 086.

Chapters 8 and 9 deal with glycoprotein characterization and analysis using HPLC and tandem mass spectrometry.

Chapter 10 highlights microarray-based carbohydrate-protein binding study.

Chapter 11 includes data about application of nuclear magnetic resonance to functional glycomics. Chapter 12 is devoted to the metabolomics in glycomics.
Chapter 13 discusses characterization of lipid-linked oligosaccharides by mass spectrometry.

Chapter 14 deals with glycomics approach to the discovery of potential cancer biomarkers.

Chapter 15 focuses on extraction methods of chondroitin/dermatan sulfate glycosaminoglycans from connective tissue for mass spectrometric analysis.

In chapter 16 there are data related to $\mathrm{N}$-linked protein glycosylation in a bacterial system.

Chapter 17 deals with characterization of polysaccharides using mass spectrometry for bacterial serotyping.

Chapter 18 describes permethylation methods applicable to protein $\mathrm{N}$-glycosylation study using as example $\mathrm{O}$-acetylation sialic acid in fish serum glycans.

Chapter 19 is dedicated to bioinformatics in glycomics using mass spectrometry data from SimGlycan informative bank.

The book will be very useful source for many researchers in glycobiology fields. It should be recommended also to students and teachers of colleges and universities who specialized in glycobiology. I would like to mention that the book is well done including a materials and methods part to each chapter, references, subject index, figures and tables. 